\title{
Medical Students in Low- and Middle-Income Countries and COVID-19 Pandemic
}

\author{
Chatpol Samuthpongtorn,' Krit Pongpirul. ${ }^{2}$
}

\section{The Experience}

The novel coronavirus disease (COVID-19) pandemic has attacked nearly every country-high- and low- and middle economies. The dividing line that dichotomizes the global population into medical staff who provide care and patients who receive care has never been this thin. In fact, healthcare providers have more likelihood of not only getting infected but also spreading the virus. ${ }^{1-3}$

As of April 14,2020, there were over 2,500 cases in Thailand and more than 2,000,000 cases worldwide. While these figures attracted the attention of any young individual to a similar extent as other international news. In many countries, schools were closed and students were asked to study at home. Likewise, pre-clinical medical students were asked to do the same. Nonetheless, medical students who are in their clinical years like myself are not qualified as a healthcare professional, yet are not regarded as layperson either. Things are complicated as conventional medical knowledge as well as clinical care and personal protective skills of medical students have not saturated, not to mention the unclear pathophysiology of the emerging virus.

During the inception of the $6^{\text {th }}$ year of my medical training in Thailand, ${ }^{4}$ in the emergency room, a 45-year-old male presented with dyspnea on exertion for one day. Despite no obvious respiratory symptoms, his oxygen saturation was about 91-92\%. Electrocardiogram showed sinus tachycardia with partial right bundle branch block and a chest $x$-ray was within normal limits. As pulmonary embolism was suspected, his blood was checked and found a significantly high D-dimer level of 700 $\mathrm{mg} / \mathrm{L}$. Consequently, computerized tomography pulmonary angiography was performed but found no blood clots in the pulmonary vessels. Instead, peripheral infiltration of both lower lungs compatible with COVID-19 was revealed. The patient was immediately moved to an airborne infection isolation room. Nasopharyngeal swab that was obtained from the patient tested positive for SARS-CoV-2 on real-time reverse-transcriptase-polymerase-chain-reaction (RT-PCR) assay.

The positive COVID-19 result in an afebrile patient with no obvious respiratory symptom was no longer a surprise, $, 5,6$ but it inevitably 'scary'. As a good medical student should do, history taking and physical examination were done intensively to approach a patientapproximately 45 minutes per patient on average in my own experience. Performing an echocardiogram on this patient to rule out structural heart disease added up exposure time. Thai medical students have been taught to take care of patients as if we were looking after our family members; it was partially acceptable to make an inconclusive diagnosis or treatment plan but unacceptable for a medical student to show inadequate compassionate care, especially in the Thai context. Unfortunately, the longer time we spend with an infected patient, the higher chance we get infected ourselves.

The moment I knew that the patient was COVID-19 positive, I started asking myself so many questions, including about the reliability of the personal protective equipment that I wore that day. Did I wear it correctly? Did I clean my hand adequately afterward? Despite the anxiety and stress while waiting for the result from laboratory investigations of hospital staff who contacted the patient, I did not feel discouraged from taking care of patients. I believe in remaining calm and finding a way to learn and practice skills through this situation. one mandatory skill for any general practitioner is endotracheal intubation. Although intubation was presumed to pose a high risk for healthcare staff during the procedure to save the life of an infected patient, such presumption might distract us from the fact that the virus could be transmitted from an asymptomatic carrier. Although physical protection is essential, I learned that ability to remain focused is crucial during the pandemic. There have been several atypical presentations of COVID-19 cases; abdominal and testicular pain, sudden loss of smell, shortness of breath without fever or respiratory symptoms, for example. Patients came to the hospital without a clue of COVID-19 so it is very difficult to indicate which patient is 'high risk'. Hence, the medical school policy to limit exposures or procedures in high-risk patients for medical students is practically questionable.

COVID-19 has a potentially significant impact on medical students and medical schools. A 26-year-old University of Louisville medical student became ill while at school but tested negative. ${ }^{8}$ After returning to her home, she was taken to the Baptist Health Lexington emergency room, tested positive for COVID-19, and had to be admitted to the intensive care unit for weeks. After she had gotten better, she still had a mildly depressed mood. Moreover, she did not know who she got infected from although nosocomial infection was likely.

Medical students in preclinical years in Thailand teaching have replaced classrooms with online sessions; the objective was to decrease the gathering of children into the crowded community and reduced physical interactions. Those in clinical years were in their questionable roles and responsibilities during their educational transition. On the contrary, the American Association of Medical Colleges (AAMC) reported at least 13 U.S. medical schools allow students to graduate early in response to the COVID-19 pandemic. ${ }^{6}$ While I hope that approach is not necessary for other countries, I am still not sure if I prefer a clear and legitimate role and responsibility as a doctor to being an in-training medical student with unclear safety skills.

\footnotetext{
1 Medical student, Faculty of Medicine, Chulalongkorn University, Bangkok, Thailand

2 Assist. Prof. MD, MPH, PhD. Faculty of Medicine, Chulalongkorn University, Bangkok, Thailand. Johns Hopkins Bloomberg School of Public Health, Baltimore, MD, USA. Bumrungrad International Hospital, Bangkok, Thailand.

About the Author: Chatpol Samuthpongtorn is currently a 6th year medical student in the Petchompoo Program of Faculty of Medicine, Chulalongkorn University, Bangkok, Thailand. He got several national awards in high school for mathematics, physics, and chemistry as well as a biomechanical engineering scholarship from USA. Currently, he is also a candidate of Prince Mahidol Award Youth Program for the year 2020. 


\section{Experience}

We believe the knowledge and skills regarding infection control in the medical curriculum, at least in low- and middle-income countries like Thailand, have been minimal to none. The COVID-19 pandemic introduced an unprecedented opportunity for medical students and a majority of medical staff to learn about the personal protective equipment (PPE) for the first time. ${ }^{3}$ This is a great starting point of a new norm in our medical society, along with the other emerging social norms such as wearing a mask and washing hands. 


\section{References}

1. Chirico F, Nucera G, Magnavita N. COVID-19: Protecting Healthcare Workers is a priority. Infect Control Hosp Epidemiol 2020 Apr 17:1-4.

2. Neto MLR, Almeida HG, Esmeraldo JD, Nobre CB, Pinheiro WR, de Oliveira CRT, et al. When health professionals look death in the eye: the mental health of professionals who deal daily with the 2019 coronavirus outbreak. Psychiatry Res 2020 Apr 13;288:112972.

3. Gallagher TH, Schleyer AM. "We Signed Up for This!" - Student and Trainee Responses to the Covid-19 Pandemic. N Engl J Med. 2020 Apr $8 .$.

4. Kittrakulrat J, Jongjatuporn W, Jurjai R, Jarupanich N, Pongpirul K. The ASEAN economic community and medical qualification. Glob Health Action. 2014 Sep $10 ; 7: 24535$.

5. Pongpirul WA, Pongpirul K, Ratnarathon AC, Prasithsirikul W. Journey of a Thai Taxi Driver and Novel Coronavirus. N Engl J Med. 2020 Mar 12;382(11):1067-1068.
6. Pongpirul WA, Mott JA, Woodring JV, Uyeki TM, MacArthur JR, Vachiraphan A, et al. Clinical Characteristics of Patients Hospitalized with Coronavirus Disease, Thailand. Emerg Infect Dis. 2020 Apr 8;26(7).

7. Kim J, Thomsen T, Sell N, Goldsmith AJ. Abdominal and Testicular Pain: An Atypical Presentation of COVID-19. Am J Emerg Med 2020 Mar 31;S07356757(20)30194-7.

8. Abrams A, Ducharme J. Meet the Medical Students Becoming Doctors in the Middle of a Pandemic. Times [newspaper on the Internet]. Last updated: Apr 13 , 2020; cited Apr 18, 2020. Available from: https://time.com/5820046/medicalstudents-covid-19/.

\section{Acknowledgments}

None.

\section{Conflict of Interest Statement at Funding}

The Authors have no funding, financial relationships or conflicts of interest to disclose.

\section{Author Contributions}

Conceptualization: CS, Investigation: CS, Supervision, Validation and Visualization: KP, Writing - Original Draft Preparation: CS, and Writing - Review $\mathrm{A}$ Editing: CS and KP.

Cite as:

Samuthpongtorn C, Pongpirul K. Medical Students in Low- and Middle-Income Countries and CoVID-19 Pandemic. Int J Med Students. 2020 Jan-Apr;8(1):7981.

This work is licensed under a Creative Commons Attribution 4.0 International License

ISSN 2076-6327

This journal is published by the University Library System, University of Pittsburgh as part of the Digital Publishing Program and is co-sponsored by the University of Pittsburgh Press. 